\title{
3D Parametric Models for 'Planterian' Vaults in Turin
}

\author{
Marco Vitali ${ }^{1}$
}

Published online: 6 April 2017

(C) Kim Williams Books, Turin 2017

\begin{abstract}
Between the end of the 17th century and early eighteenth centuries Guarino Guarini and Gian Giacomo Plantery produced a revolution in the way vaulted systems for atria of palaces in Turin were conceived. 'Star-shaped' and 'planterian' vaults created a new trend that would persist for nearly sixty years. The wide-spread use and variety of planterian vaults has been the focus of a research project that began in 2012. This research, by comparing similar atria and their digital models, has made it possible to work on a multi-variable model aimed to represent the generic surface of any planterian vault whatsoever by using parameters, and consequently to draw the individual cases studied by associating the appropriate values to each parameter.
\end{abstract}

Keywords Planterian vaults · Gian Giacomo Plantery · Piedmontese architecture · Parametric modelling · Geometry of vaults

\section{Introduction}

Between the end of the seventeenth century and early eighteenth centuries, there was a revolution in the way spatial-geometric models of vaulted systems were conceived for the atria of palaces in Turin. This was a crucial issue in the research on vaulted systems by Piedmontese Baroque architects, especially that by Guarino Guarini, Gian Giacomo Plantery, and Bernardo Antonio Vittone (Piccoli 1999, 2001; Cavallari Murat 1957). The compositional tradition of the sixteenth and early seventeenth centuries almost always organized halls and galleries with a regular sequence of vaulted modules (sail or groin vaults) that divided the space according to uniform

Marco Vitali

marco.vitali@polito.it

1 Department of Architecture and Design (DAD), Politecnico di Torino, Turin, Italy 
rhythms. In the sixteenth century, most of the atria of buildings in Turin were adaptations of the late medieval and Renaissance buildings to the taste and needs of the time. In a subsequent period, however, this scheme outlined new buildings of remarkable representative value, with great halls through the ground floor (Cavallari Murat 1968b; Vitali 2016). The compositional schemes fully developed in the seventeenth century became obsolete, and at the end of the seventeenth century, Guarino Guarini proposed some unusual radiocentric compositional schemes that are the first examples of 'star-shaped' vaults (Dardanello et al. 2006).

The Palazzo Carignano (1679) and Palazzo Provana di Collegno (1687) are good examples of Guarino Guarini's new experiments: the entrances and both the distribution and reception systems are ordered in a sequence of spaces with a central plan. The main rooms show star-shaped vaults, which are large and low without intermediate pillars and consist of a main oval-shaped surface with homogeneous lunettes (constituted by surfaces of the same type) placed radially. The projection in plan of the lunettes is triangular. These schemes reverberate in the work of Michelangelo Garove, one of Guarini's followers, with the Palazzo Asinari di Sanmarzano (1684) (Fig. 1).

A young Gian Giacomo Plantery (1680-1756) then adapted the star-shaped scheme to a rectangular plan. This led to the construction of the Palazzo Novarina di

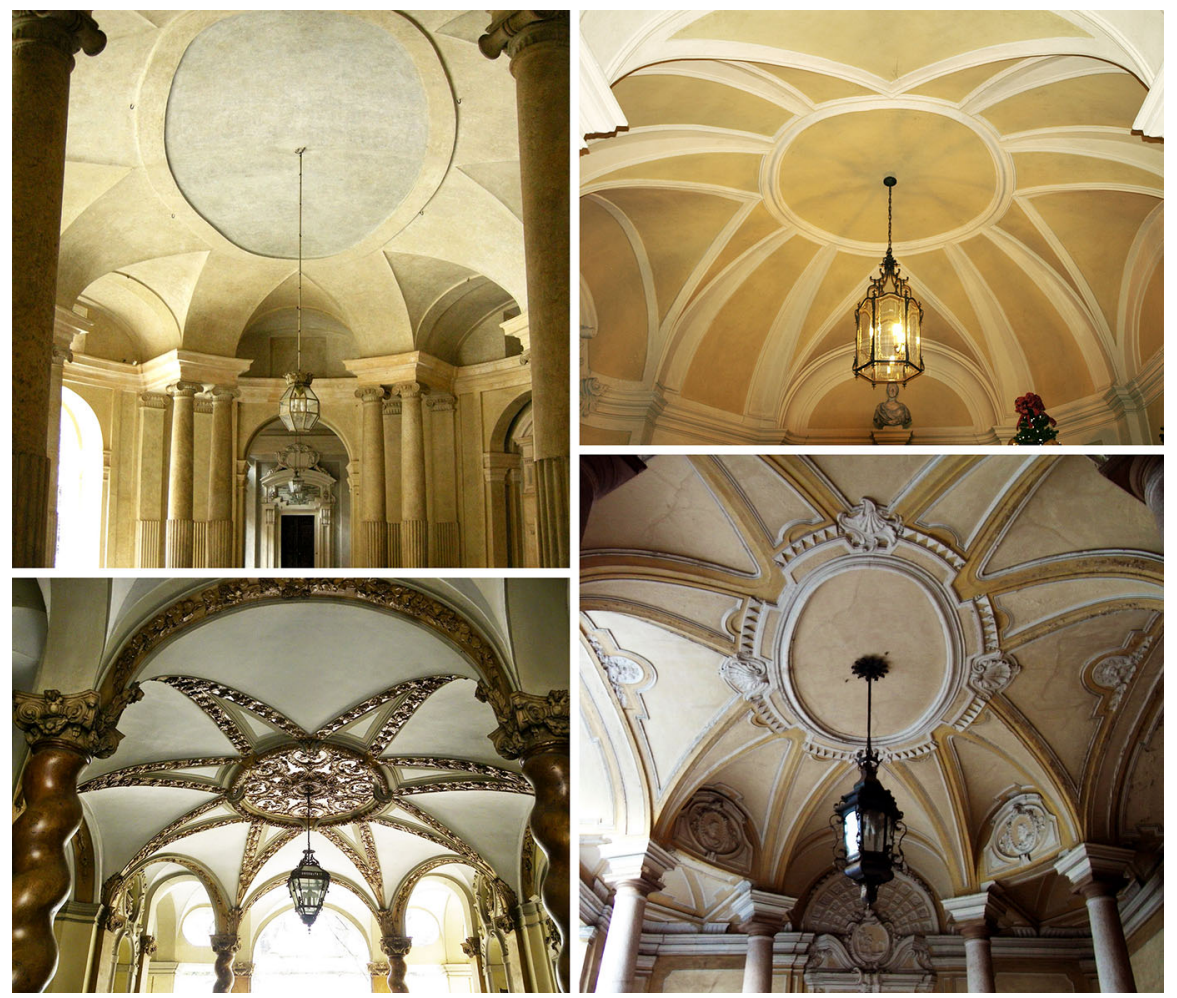

Fig. 1 Star-shaped vaults in the historic city centre of Turin, identified by their addresses: Piazza Carignano 5 (Palazzo Carignano), via Maria Vittoria 4 (Palazzo Asinari di San Marzano), via Santa Teresa 20 (Palazzo Provana di Collegno), Piazza San Carlo 197. Photo: Author 
San Sebastiano (1700-1710) and Palazzo Cigliano (1707) in Turin. Both of these reflect seventeenth-century taste that incorporates and interprets the scheme adopted by Michelangelo Garove in order to adapt the star scheme to the rectangular layout. The more mature, individualistic designs of the Palazzo Saluzzo Paesana (1715) and Palazzo Cavour (1729) finally emerged as models of the so-called 'Planterian' vaults, which created a distinct new trend in the works of many Turin architects that would persist for nearly 60 years. Not only did the new form become a formal and decorative reference, but it also paved the way for practices and building techniques shared by both architects and masons (Fig. 2).

Planterian vaults consist of a main ' $a$ conca' (shell-like) surface: secondary surfaces (along the longitudinal and transverse axes) and angular surfaces insert on it. The projection in plan of the secondary and angular surfaces is a curved line.

In regard to the definition of the 'a conca' vault it is necessary to refer to a typical local habit: the definition of it provided by Palladio and Guarini refer respectively to the barrel vault with cloister heads vault and to the cloister vault (Spallone and Vitali 2015: 26-30). Further, Crugnola didn't provide a definition adapted to the case studied, so the translation in English does not seem appropriate. Instead, for the Planterian vaults the definition by Giovanni Curioni (1868: 238-239) seems to be the proper one. The 'a conca' vault, paraphrasing Curioni's definition, is defined as a surface generated by elliptical or polycentric sections that form an orthogonal grid,
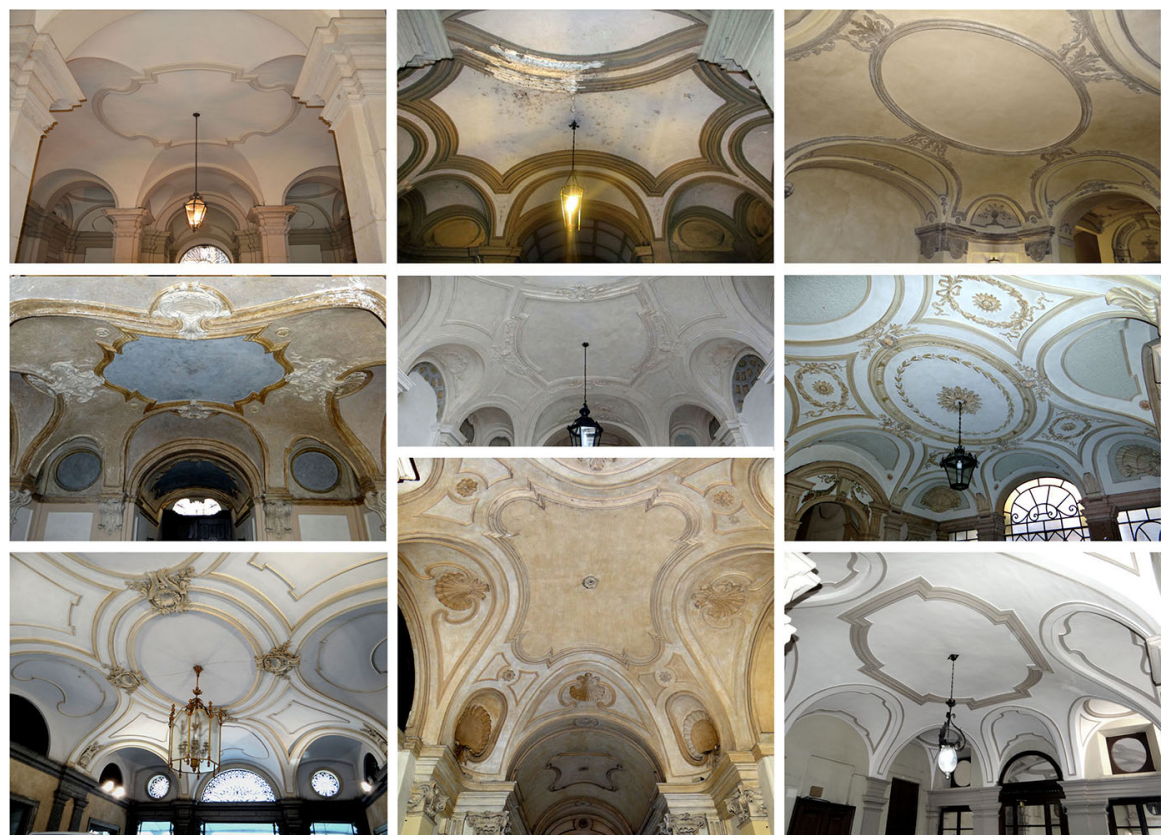

Fig. 2 Planterian vaults in the historic city centre of Turin, identified by their addresses: via della Consolata 12, via Corte d'Appello 13, Piazza Emanuele Filiberto 15, via Santa Chiara 8, via Botero 8, via Barbaroux 25, via Santa Teresa 1 g, via Santa Teresa 10, via Garibaldi 53. Photo: Author 
on which it is possible to set a vaulted surface resting continuously on the perimeter walls.

The wide-spread use of such vaults and their variety have been the focus of a research project in collaboration with Roberta Spallone begun in 2012 (Spallone and Vitali 2012a, b, c, 2015). The research was carried out in Turin and has identified more than fifty atria with both star-shaped and Planterian vaults (Fig. 3), as well as a dozen atria with 'a fascioni' vaults based other models by Guarini, described and translated in English as 'Barrel vault with projected arches' by Crugnola (18831908: V, 80).

The 'a fascioni' vault is constituted by weaved arches parallel to the two axes (longitudinal and transverse) which subdivide the vault into areas: the surfaces, which cover each area leaning on the arches, are independent. Figure 4 shows the comparison of plans and spatial configurations of the three different types of vaults identified and shown in the map.

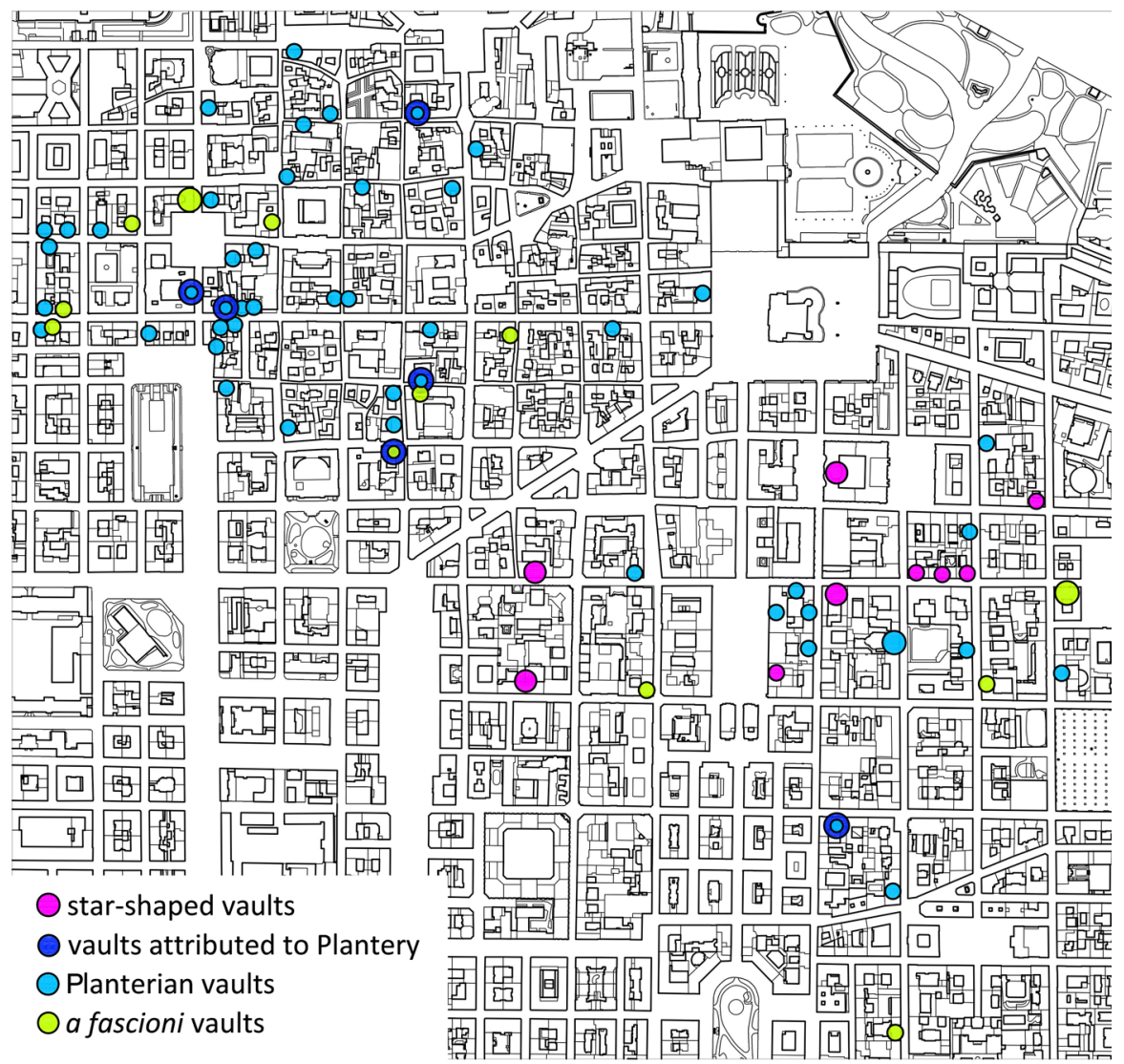

Fig. 3 Map of the historic city centre of Turin with the localization of categorized buildings: star-shaped vaults, vaults attributed to Plantery, Planterian vaults, 'a fascioni' vaults. Map: Author 

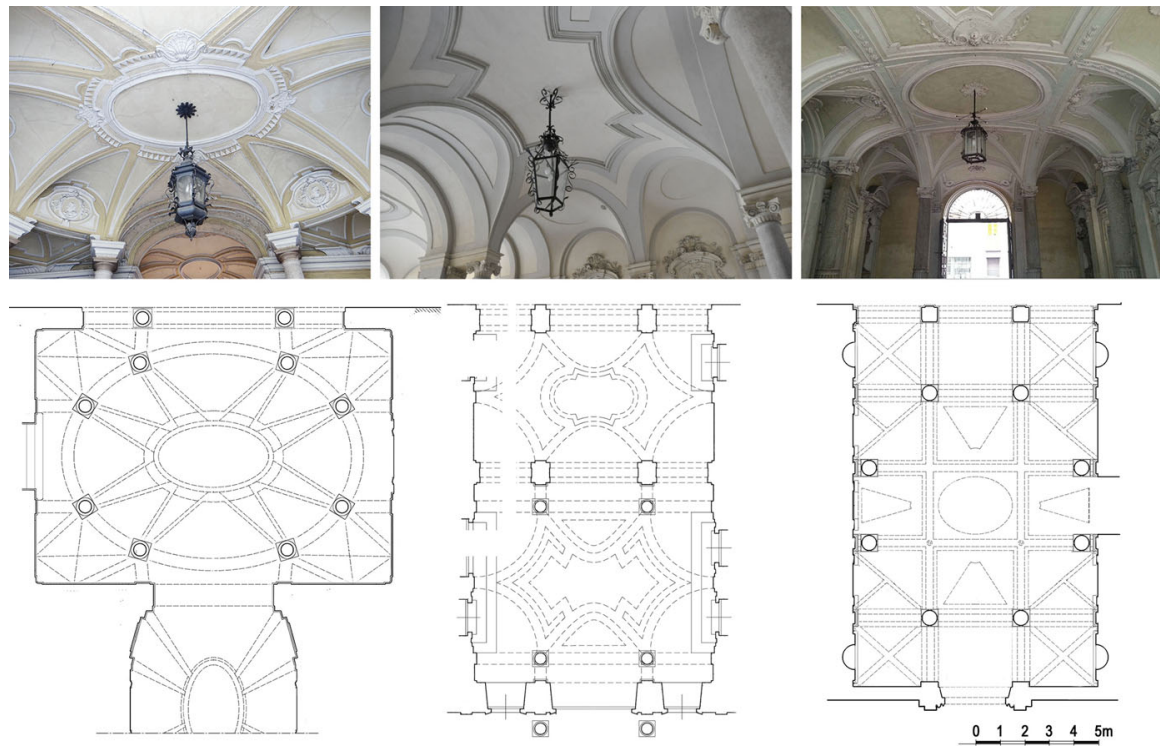

Fig. 4 Star-shaped vaults, Planterian vaults and 'a fascioni' vaults: the analysis of the plans highlights the different spatial configurations, shown by photographs. From left to right, the atria identified by their addresses: via Santa Teresa 20 (Palazzo Provana di Collegno), via Cavour 8 (Palazzo Cavour), via Maria Vittoria 26 (Palazzo Palazzo Coardi di Carpenetto). Drawings: Author, Roberta Spallone; Photo: Author

The study of these elements is currently in its initial stages. In-depth study has been focused on several significant case studies and has led to hypotheses concerning the geometric structure of the shapes, which were then modelled digitally. The hypotheses were then verified by surveying the intrados and investigated in light of both the architecture style and construction techniques gleaned from treatises and manuals on the art of building (Spallone and Vitali 2015).

Case studies have been geometrically interpreted using three-dimensional modelling software to describe and qualitatively visualize the composition and intersection of geometric surfaces identified (Fig. 5).

The three-dimensional digital modelling preceded two-dimensional drawings in our method and made it possible to verify the sections and intersections of complex surfaces by comparison with hypotheses about their conformation. The traditional graphic representation completes our understanding of the forms in space in plans and sections, where the virtual projections of the vault system are by projections and sections of the three-dimensional model.

\section{Theoretical and Methodological Premises}

The present research sets new goals of developing a system of analysis and previous results and models in order to provide a new interpretation that facilitates and supports comparisons with new three-dimensional parametric models using a 

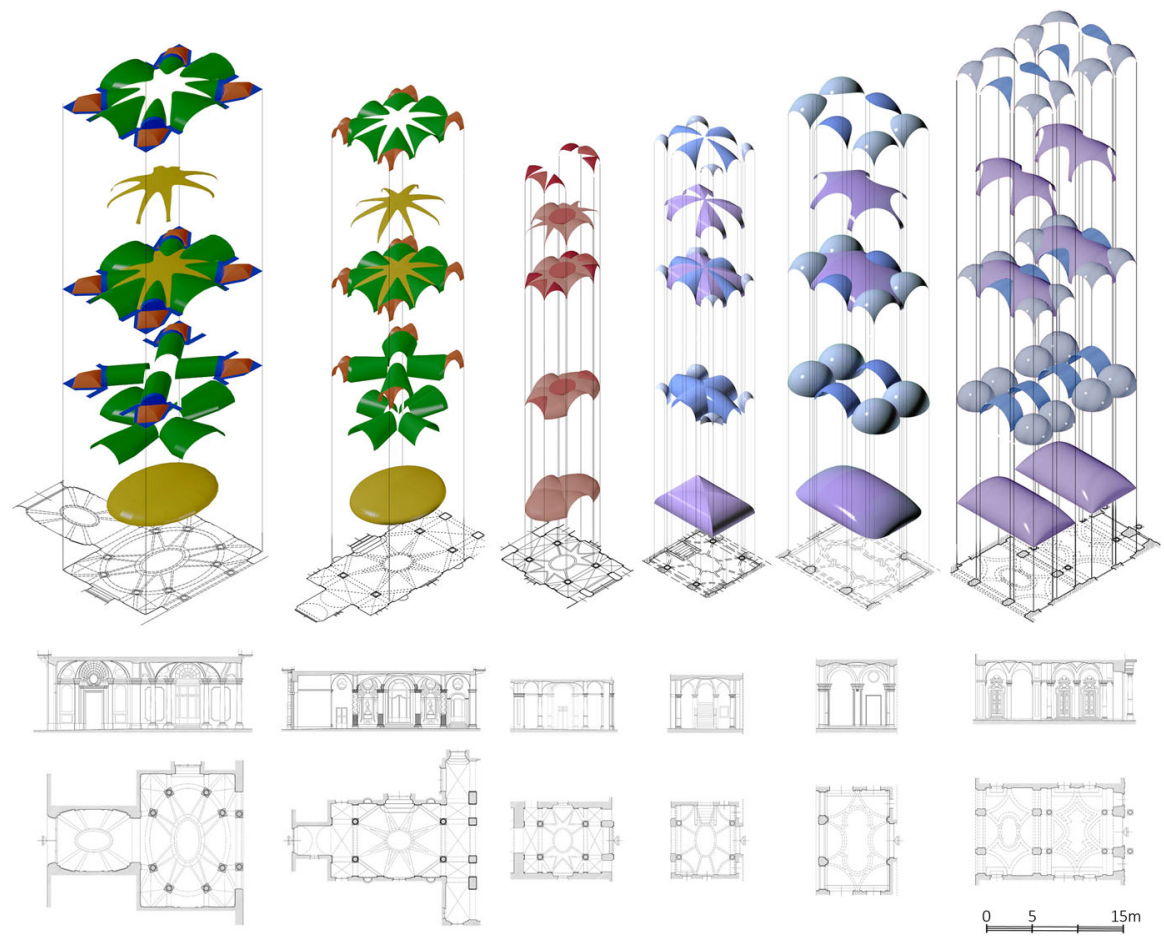

Fig. 5 Synoptic scheme of some investigated atria with plan, section and axonometric views of the threedimensional models for the analysis and comparison of surface-intersections. Star-shaped vaults: via Santa Teresa 20 (Palazzo Provana di Collegno), via Maria Vittoria 4 (Palazzo Asinari di San Marzano). Planterian vaults: via Santa Chiara 8 (Palazzo Novarina), via Barbaroux 28 (Palazzo Cigliano), via della Consolata 1bis (Palazzo Saluzzo Paesana), via Cavour 8 (Palazzo Cavour). Drawings and models: Author, Roberta Spallone

mathematical approach. According to Riccardo Migliari (2012: 564), "[W]e can recognize two main procedures in representing three-dimensional shapes: the first uses equations and thus describes the curves and the surfaces with continuity [mathematical representation]; the second uses a list of coordinates of points and rules to connect them [numerical representation]". However, both approaches are handled by applications using both methods to varying degrees, because visualization requires the discretization of the mathematical model, and the management of the numerical model requires mathematical functionalities, even if the difference between them is substantial. Furthermore, the potentials of the approaches must be considered in relation to the purpose of the research in each of the cases studied.

Our analysis allows us to consider the close connection between the geometry of the forms involved and the mathematical formulation and to assume a comprehensive system to contain all the schemes of vaults examined by putting them together in a multi-variable model. In order to reach this goal, it seems attractive to redefine digital models previously built on the logic of numerical modelling in order to create a single new model through mathematical modelling. This would be 
accomplished by mathematically defining the shapes and associating them with an adequate number of parameters to describe their variability. It would then be possible to set up a model that describes a generic surface of any Planterian vault using mathematical formulas and to draw the individual cases by associating the appropriate values with each parameter.

This possibility has been very interesting as an original idea that we have dealt with in the early stages of the research. It produced some important open questions regarding the general structure of the model, and particularly the identification of the mathematical parameters needed to build it. In regard to the mathematical parameters, it was very alluring to describe architectural shapes using formulas, but there was a discrepancy between survey data that measure the quality of architecture and mathematical parameters that rule the theoretical surfaces associated with them. The data available for the realization of such a parametric model are the survey data, which do not constitute elements with which the parameters that control the mathematic formulation of surfaces are directly associated in most cases.

As an example, for the description of an elliptical arc, the relevant data that describe its shape are the height of the impost plan, the rise, the span itself, and the position of a set of control points. Using such measures, it is easy to find the values corresponding to the mid-axes $a$ and $b$, which are the denominators in the generic formula of an ellipse. However, most of the surfaces involved in the composition of a complex vault, as in the case of Planterian vaults, are constructed using methods that show some difficulty in identifying the mathematical parameters, the fields for their formulation, and other information. The main surfaces are built of variable sections, and the secondary sections arise from translation of a section along a path. For these surfaces, the mathematical formulation is of course possible, but the governing parameters do not always correspond to measurable distances in actual architecture. Furthermore, the survey measurements needed to describe the geometry with which they intersect do not have an immediate relation with parameters in the formulas. For these reasons, it seems a bit artificial to describe such surfaces mathematically. A much more reasonable approach seems to be setting up a parametric model that is built and configured in relation to the architectural survey data.

Among the criteria for the general setting of the parametric model, a further specification is required. The idea of creating a parametric model of built architecture is a very ambitious goal, and it is necessary to understand exactly the purposes and modes of use (Davis 2013: 14-48). This would make it possible to accurately identify which parameters must be set for the construction of the model and how many. A parametric model that accurately represents the survey data would necessarily be very complex since it should take into account not only the geometric compositional aspects of different solutions for different vaulted surfaces, but also construction aspects and irregularities of the building.

In regard to the geometric-compositional matrices, the many characteristics or specific solutions would multiply uncontrollably when describing the examples analysed with a high level of metric precision: 
- Some surfaces or peculiar sections may be lifted up from the impost;

- Some geometric entities may be composed of non-generic sections. For instance, many arches and peculiar sections would be more accurately described as polycentric arches and not as elliptical;

- Some surfaces considered for the axial and diagonal intersections may be constructed with higher accuracy by identifying generating sections that vary continuously along their directions of development;

- The generic scheme of the plan in many cases has small deviations from the alleged longitudinal and transverse axial symmetry;

- The decoration less often follows recurrences and similarities in the cases examined and constitutes an aspect that does not lend itself to parameterization.

The structural irregularities and the parameters for their description would add to the complexity and should take into account:

- Irregularities in the plan;

- Local relative sags of surfaces caused by structural settlement;

- Inaccuracies and/or adjustments made in the construction.

All of this should be openly acknowledged against the objectives that we set: it would make the construction of the model itself enormously unwieldy, it would require the insertion of an excessive number of parameters, and it would make the use of the model challenging for the description of the different cases. Assuming the model is controllable and accessible, its metric accuracy would go against the desire to build a tool that enables agile comparisons between the studied architectures and rapid geometric simulations of objects yet to be studied.

In light of these considerations, it was considered appropriate to limit the number of parameters and sacrifice some of the opportunity to describe a measured surface, which can be described more easily by other instruments and with survey accuracy that requires much more binding measurements. This is done to represent the main spatial quality of architecture under varying parameters. The model is thus aimed at reproducing the theoretical models underlying design concepts while renouncing the chance to consider all the variables of the construction to enable rapid and efficient exploration of the different geometric configurations and easy comparison between them. Therefore, a simple parametric model should represent the spatial qualities of the various architectures while highlighting similarities and differences, and lend itself easily to implement a catalogue of identified buildings without requiring input data that require the precision of an instrumental survey.

\section{Geometric Genesis and Constructional Logics: Limits and Potentialities of the Parametric Model}

It was possible to do a comparative study of the different models following the construction and formalization of the models of the Planterian vaults identifiedfirst, those that are surely attributed to Plantery, and second, some of the most significant in regard to geometric complexity and structure. This conjectural reading 
shows recurring approaches in the composition of the vaulted structures, variants and invariants of the plan, and simple geometric forms involved. For the sake of simplicity, the different vaulted surfaces are categorised as star-shaped and Planterian vaults, which can be distinguished by two different approaches to the geometries that characterize them: construction by 'cuts and fills' and construction by 'intersections'.

The 'cuts and fills' method works perfectly for the description of all the starshaped vaults, in accordance with Guarini's atria, and for some typical examples of the transition from star-shaped to Planterians, including the first designs achieved by Plantery as he searched for the perfect solution integrating the vaulted surface on a quadrangular plan. The 'intersections' method is apt for the description of many of the examples made by Plantery and his contemporaries, starting from the emblematic achievements of the Palazzo Saluzzo Paesana and Palazzo Cavour. The 'cuts and fills' method involves the construction of a complex vault starting from a plan drawing (Spallone 2016), and the main surface is cut by vertical auxiliary planes used to subtract portions of it. Such cuts generate sections on which it is possible to construct secondary and angular vaults by using new surfaces generated by sections. It is rather factitious in the analysis of such surfaces to imagine that secondary and angular vaults can be traced back to primitive geometric surfaces. The regularity of the cuts by vertical planes and the ductility of surfaces in joining up curves such as arches which do not lie on parallel planes suggest that they have been conceived as surfaces set by sections that depend strictly on the plan, even before the construction.

The second type of vaults consists of a main surface on which secondary and angular surfaces are articulated, which produce intersections that develop in space and generate three-dimensional arches. Generally, for Planterian vault plans, the rectangular layout is divided into three segments on the long side (usually transverse to the direction of entry) and two or three segments on the short side. The surfaces defining the vault overlap this scheme and normally generate longitudinal, transverse, and diagonal connections. In relation to this simplification, Augusto Cavallari Murat identified the most recurrent plan schemes and tried to systematize them in summary tables of the main spatial characteristics, highlighting their similarities and differences (Cavallari Murat 1968a: 109). The surface of Planterians vaults can be described by:

- A main surface almost always made up by an 'a conca' (shell-like) vault. It works very well for covering regular/irregular rooms, rectangular rooms, octagonal rooms, etc.;

- Axial secondary surfaces that intersect the main surface can be assimilated into cylindrical or toric surfaces generated by translating a characteristic section along a straight path (horizontal or inclined) or constituted by an arc;

- Angular vaults can be equated to spherical or ellipsoidal surfaces with an equatorial section that is set through three points on the impost.

In summary, for obvious reasons, it is not possible to constitute a parametric model that is functional for both star-shaped and Planterian vaults, given their different spatial geometric genesis. Based on previous research and on a 
Table 1 Planterian vaults identified by their addresses: they have been analysed in relation to the geometric construction ('cuts and fills', 'intersections') and the correspondence of the surfaces to those used for the construction of the parametric model

\begin{tabular}{|c|c|c|c|c|c|c|c|}
\hline \multirow{2}{*}{$\begin{array}{l}\text { type of } \\
\text { vault }\end{array}$} & \multirow[t]{2}{*}{ address } & \multirow[t]{2}{*}{ geometry } & \multicolumn{4}{|c|}{ surfaces } & \multirow{2}{*}{$\begin{array}{c}\text { parametric } \\
\text { model }\end{array}$} \\
\hline & & & 1 & 2.1 & 2.2 & 3 & \\
\hline planterian & piazza Savoia 4 & intersections & yes & yes & yes & yes & $\bullet$ \\
\hline planterian P & via Barbaroux 28 & cuts and fills & no & no & no & yes & 0 \\
\hline planterian & via Barbaroux 43 & intersections & yes & yes & yes & yes & - \\
\hline planterian & via Barbaroux 25 & intersections & yes & yes & yes & - & - \\
\hline planterian & via Bligny 0 & intersections & no & yes & yes & - & 0 \\
\hline planterian & via Bogino 8 & intersections & yes & yes & yes & no & $\bullet$ \\
\hline planterian & via Botero 8 & intersections & yes & yes & yes & yes & $\bullet$ \\
\hline planterian & via Carlo Alberto 32 & intersections & no & yes & yes & no*2 & 0 \\
\hline planterian & via Carlo Alberto 16 & intersections & no & - & yes & yes & 0 \\
\hline planterian $\mathrm{P} * 2$ & via Cavour 8 & intersections & yes & yes & - & yes & $\bullet$ \\
\hline planterian & via Corte d'Appello 13 & intersections & yes & yes & yes & yes & $\bullet$ \\
\hline planterian & via del Carmine 4 & cuts and fills & yes & no & no & yes & 0 \\
\hline planterian & via della Consolata 12 & intersections & yes & yes & yes & yes & $\bullet$ \\
\hline planterian P & via della Consolata 1 bis & intersections & yes & yes & - & yes & $\bullet$ \\
\hline planterian & via della Consolata 8 & intersections & yes & yes & - & yes & $\bullet$ \\
\hline planterian & via Garibaldi 37 & intersections & yes & yes & yes & yes & $\bullet$ \\
\hline planterian & via Garibaldi 40 & intersections & yes & - & - & yes & $\bullet$ \\
\hline planterian & via Garibaldi 53 & intersections & yes & yes & yes & yes & $\bullet$ \\
\hline planterian & via Garibaldi 39 & intersections & yes & - & yes & yes & $\bullet$ \\
\hline planterian & via Garibaldi 23 & intersections & yes & yes & yes & yes & $\bullet$ \\
\hline planterian & via Garibaldi 24 & intersections & no & yes & yes & yes & $\bullet$ \\
\hline planteriana P & via Garibaldi 28 & intersections & no & yes & yes & no*2 & o \\
\hline planterian & via Lagrange 6 & intersections & yes & yes & yes & yes & $\bullet$ \\
\hline planterian & via San Fr. da Paola 17 & intersections & no & yes & yes & - & $\bullet$ \\
\hline planterian P & via Santa Chiara 8 & cuts and fills & yes & yes & no & no*2 & 0 \\
\hline planterian & via Santa Chiara 20 & intersections & yes & yes & yes & no & $\bullet$ \\
\hline planterian & via Santa Teresa 10 & intersections & yes & yes & yes & - & $\bullet$ \\
\hline planterian & via Santa Teresa $1 \mathrm{~g}$ & intersections & yes & yes & yes & no & $\bullet$ \\
\hline planterian & via Sant'Agostino 2 & intersections & yes & yes & yes & yes & $\bullet$ \\
\hline planterian & via Sant'Agostino 1 & intersections & yes & yes & yes & yes & $\bullet$ \\
\hline
\end{tabular}

(1) Main surface; (2) Axial secondary surfaces (2.1-longitudinal, 2.2-transverse); (3) Angular surfaces. $\mathbf{P}$ are attributed Plantery; yes when the surface matches the parametric model; no when the surface doesn't match the parametric model; - when the surface doesn't exist in the case; *2 for double complex surfaces;

- Adequate; $\bigcirc$ Not adequate; $\bigcirc$ Adequate but with some deviation. Table: Author

categorization of the different surveyed vaults, Table 1 was established based on the geometric characteristics and generative logic for quantitative analysis to make a reasonable choice.

The characteristics of only the Planterian vaults are listed in Table 1 and were obtained from a sample of 73 vaults identified on the map in Fig. 3, which includes star-shaped vaults (9), Planterian vaults (31), 'a fascioni' vaults (12), and other 
types of complex vaults that are not relevant to this study (21). The vaults are identified by their addresses and have been analysed in relation to the geometric construction ('cuts and fills', 'intersections') and the correspondence of the surfaces to those used for the construction of the parametric model:

1. Main surface: 'a conca' vault;

2. Axial secondary surfaces (2.1-longitudinal, 2.2-transverse): cylindrical or toric surfaces generated by translating an elliptical section;

3. Angular surfaces: spherical or ellipsoidal surfaces.

The last column shows the adequacy of the parametric model for the vault with values that indicate the following:

Adequate (19);

Not adequate (7);

- Adequate but with some deviation (5).

These results address the choices concerning the construction of the parametric model and suggest proceeding an 'intersections' model, which was adapted to a wider number of studied cases. A 'cuts and fills' parametric model will be the subject of future studies.

\section{Construction of the Parametric Model}

The parametric model was realised using Grasshopper software for Rhinoceros $5^{\circledR}$. The main goal is to build a structure that is more flexible towards the analysed geometries. Figure 6 shows the Grasshopper visual script used for the parametrization of the whole vaulted system, organized (from left to right) with general dimensions of the room, features of the involved surfaces (principal, secondary and angular), ways in which they constitute by intersection and subtraction the final surface: in this regard, for a correct display of the vault it is necessary to switch off the visual effect of many blocks of the visual script, even if they are needed to get the final result.

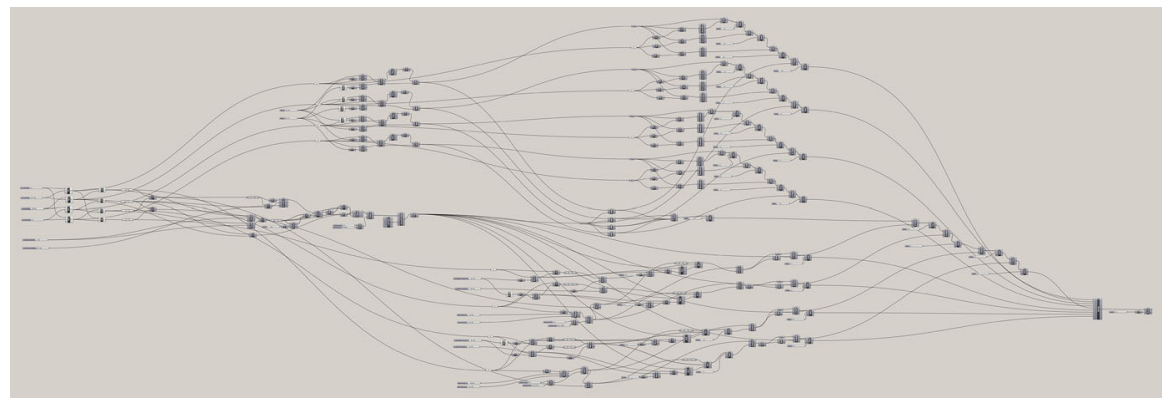

Fig. 6 Visual script of the parametric model. Model: Author 

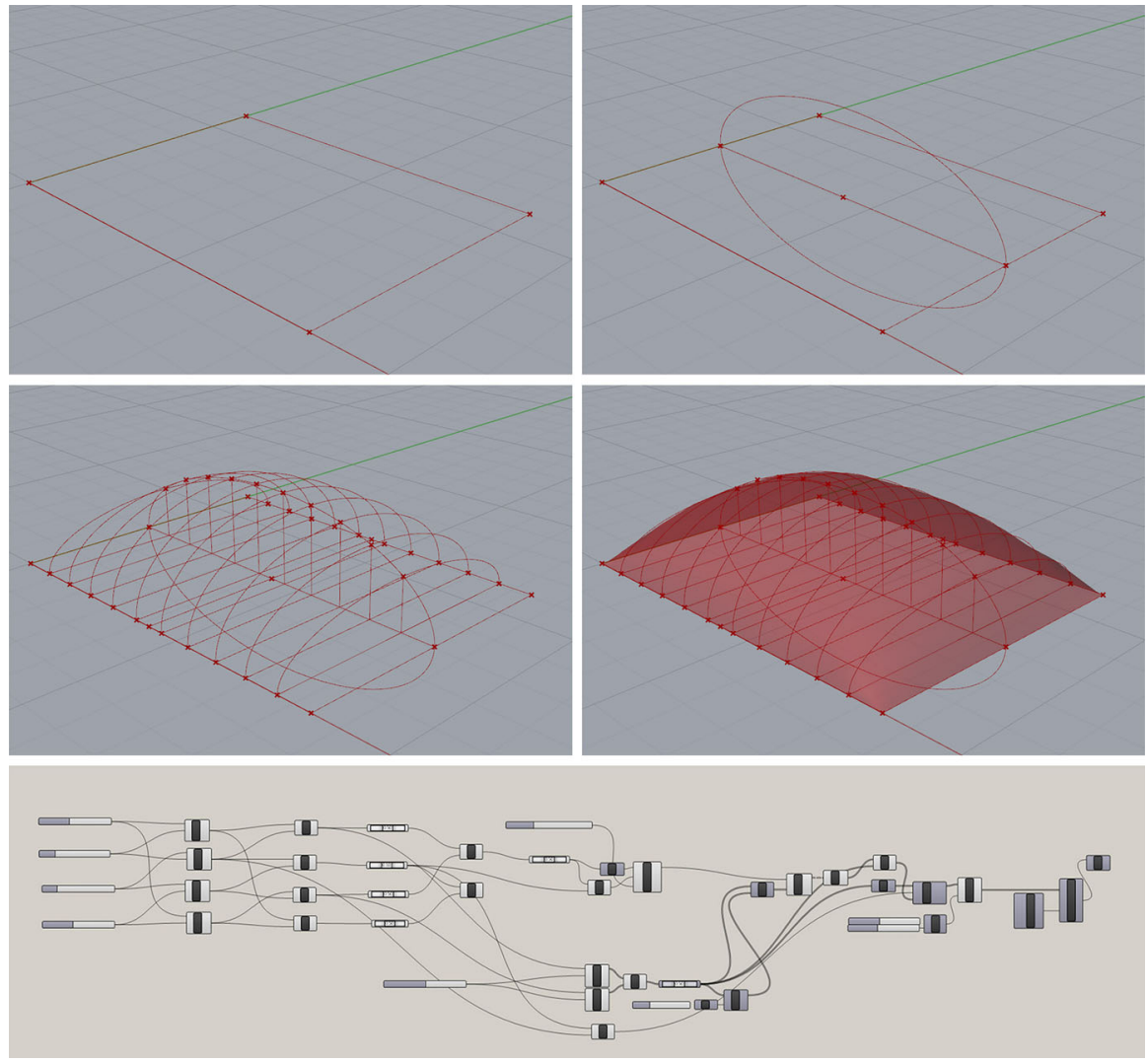

Fig. 7 Parametric model: construction by steps of the main surface. Model: Author

We now proceed to the description of the key stages of the model construction: the construction of the main surface, the axial (longitudinal and transverse) secondary surface, the angular surfaces, and the intersections between surfaces. For each key stage of the construction of the model a figure shows the salient geometric passages and a zoom of the visual script of the illustrated operations.

\section{1) Construction of the main surface (Fig. 7)}

The construction of the main surface is based on the geometry of the ' $a$ conca' vault, which is suitable in most of the cases. The parameters that manage the coordinates of the four corner points of the vaulted space were set to obtain a theoretical surface, with coordinates $(0,0)$ on the horizontal plane representing the origin point and tying the coordinates of the other points to the length and width parameters of the room such that a regular plan is always the result (step 1). Subsequently, the midpoints on a pair of sides were identified with the main elliptical section of the surface parameterized to represent the height of the keystone (step 2). The sides parallel to the main section were divided into $n$ equal parts defining $n$ parallel vertical planes to construct perpendicular secondary elliptical 
sections passing through points on the perimeter and corresponding points on the main section. In this way, the user can easily decide, with the number of secondary sections perpendicular to the main one, the level of discretization of the vaulted surface (step 3). The model of the main vault can be realized, using a 'loft' operation, by the construction of a surface passing through these sections including the two bound sections corresponding to the perimetric sides of the room (step 4).

\section{2) Construction of secondary axial surfaces (Fig. 8)}

For the construction of the secondary surfaces, elliptical sections were set with centres on the midpoints of the sides of the room, for which it is possible to define (two pairs of sections on the opposite sides of the perimeter) the two axes using parameters (step 1). The parameters that define the points with a maximum distance from the perimeter on the footprint of the intersection between the main and

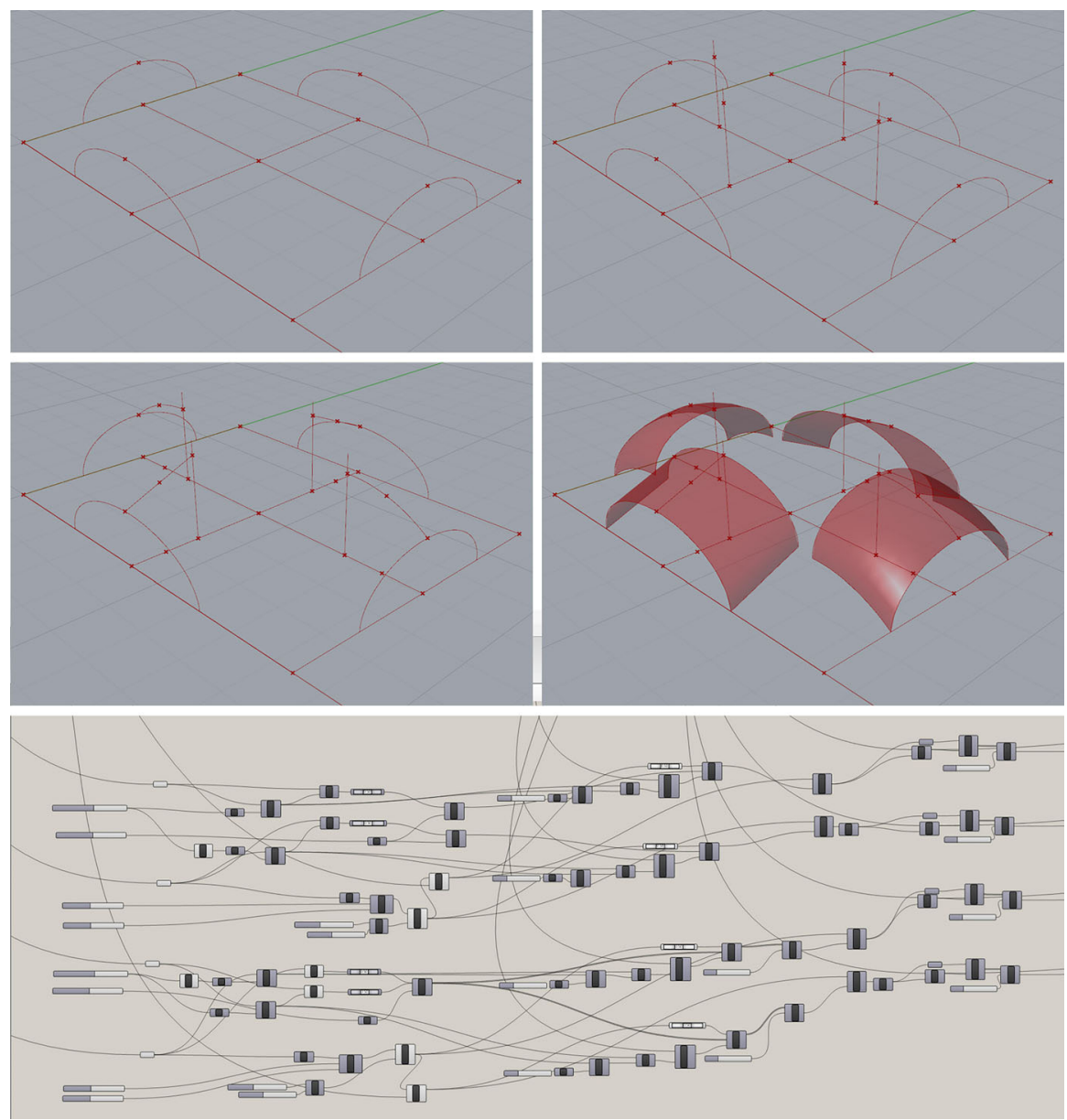

Fig. 8 Parametric model: construction by steps of secondary axial surfaces. Model: Author 
secondary surface (two pairs of points and two parameters) were then built, and their corresponding points (along the vertical direction) on the main surface were identified (step 2). Two new pairs of parametric points were added to define the extrusion path of the semi-elliptical section (step 3): along an horizontal or inclined straight line (in order to obtain straight or inclined barrel vaults) or along a part of a circle (in order to obtain toric surfaces) (step 4).

3) Construction of angular surfaces (Fig. 9)

For the construction of the angular surfaces it is necessary to construct the arches that define its sections along the perimeter of the room. These arches occupy the remaining portions of the perimeter sides, which are usually divided into three parts

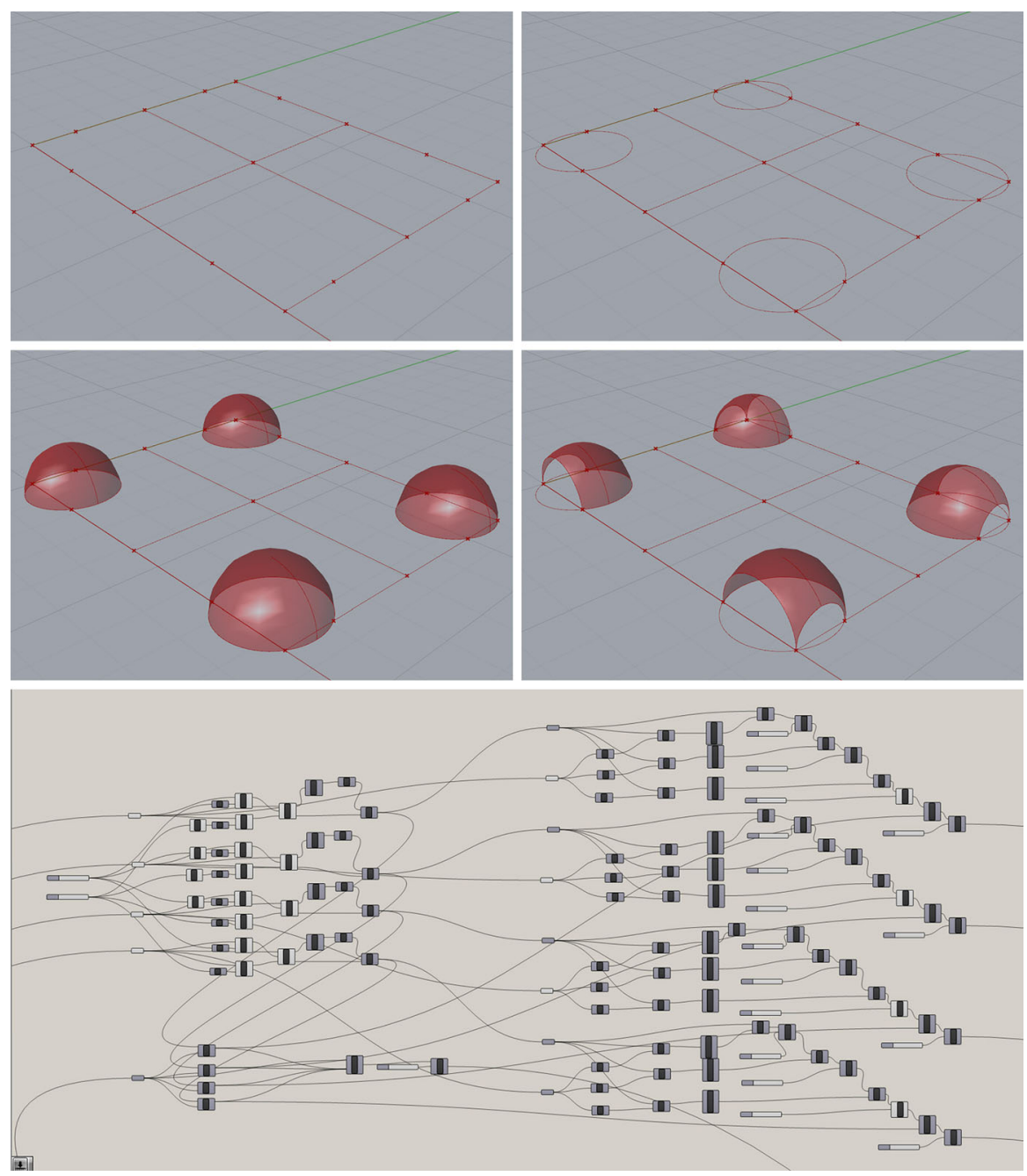

Fig. 9 Parametric model: construction by steps of angular surfaces. Model: Author 
interspersed with pilaster strips. Points that define the span of these additional arches (two groups of four symmetrical arches) were parameterized starting from the corners. Thus, four symmetrical sets of three points were defined (corner point and spans of two arches for each corner, step 1), and the horizontal section (on the impost plane) of angular surfaces is made to pass through them (circle by three points, step 2). This is a clear simplification of the problem since the horizontal sections may also be elliptical. However, this step is necessary since it is not possible to define an ellipse for three points. Even without considering the rotation of the axes of the ellipse with respect to the perimeter sides of the room, a fourth point would be needed to identify the elliptical horizontal section of the angular surface. However, this fourth point does not exist in the survey data, so this important simplification is obligatory.

The hemispherical caps that constitute the geometry of the angular surfaces are constructed through a $180^{\circ}$ revolution of horizontal half-sections (step 3). They can be edited through an additional parameter that scales the vertical axis of the surface, which produces ellipsoidal surfaces with a vertical rotation axis. The surfaces obtained were then cut with vertical planes corresponding to the perimeter sides of the room, generating spherical or ellipsoidal half shells cut in sail vaults (step 4).

4) Construction of intersections between the different surfaces (Fig. 10)

The final version of the vaulted surface (step 4) is generated after subsequent steps: it is obtained by intersecting and subtracting each single surface (axial, step 2; angular, step 3) with the main surface (step 1).
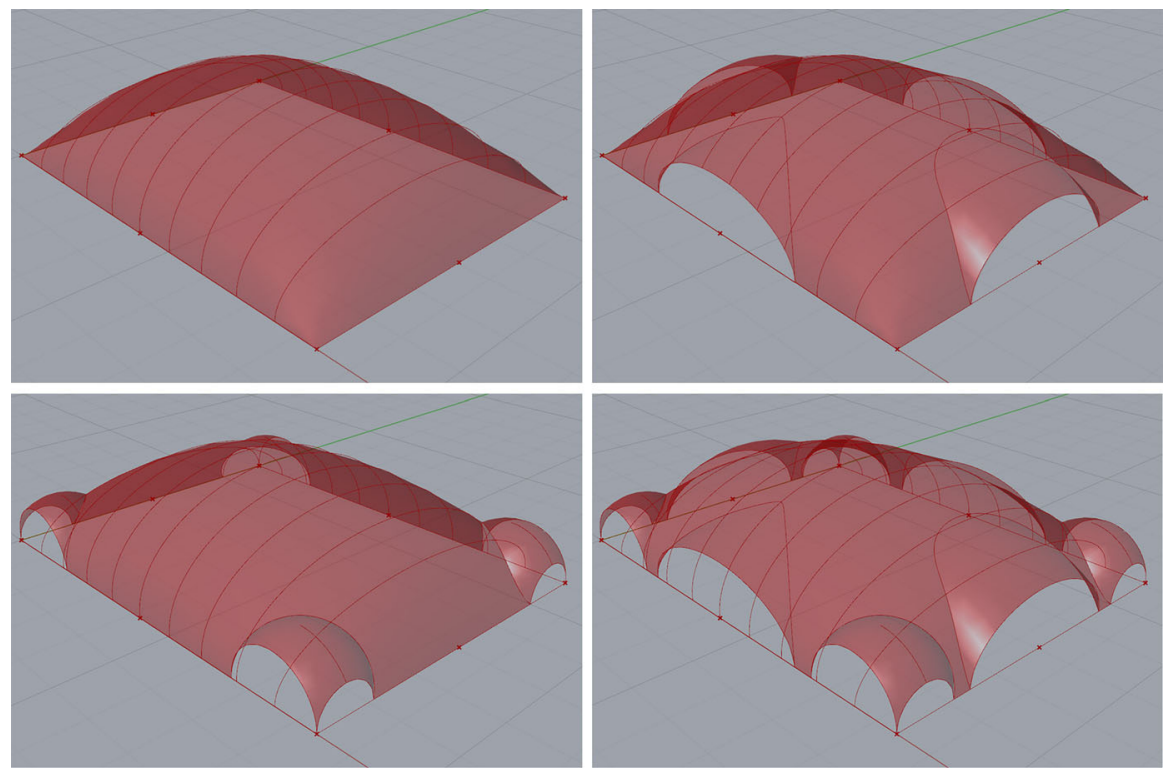

Fig. 10 Parametric model: construction of intersections between the different surfaces. Model: Author 


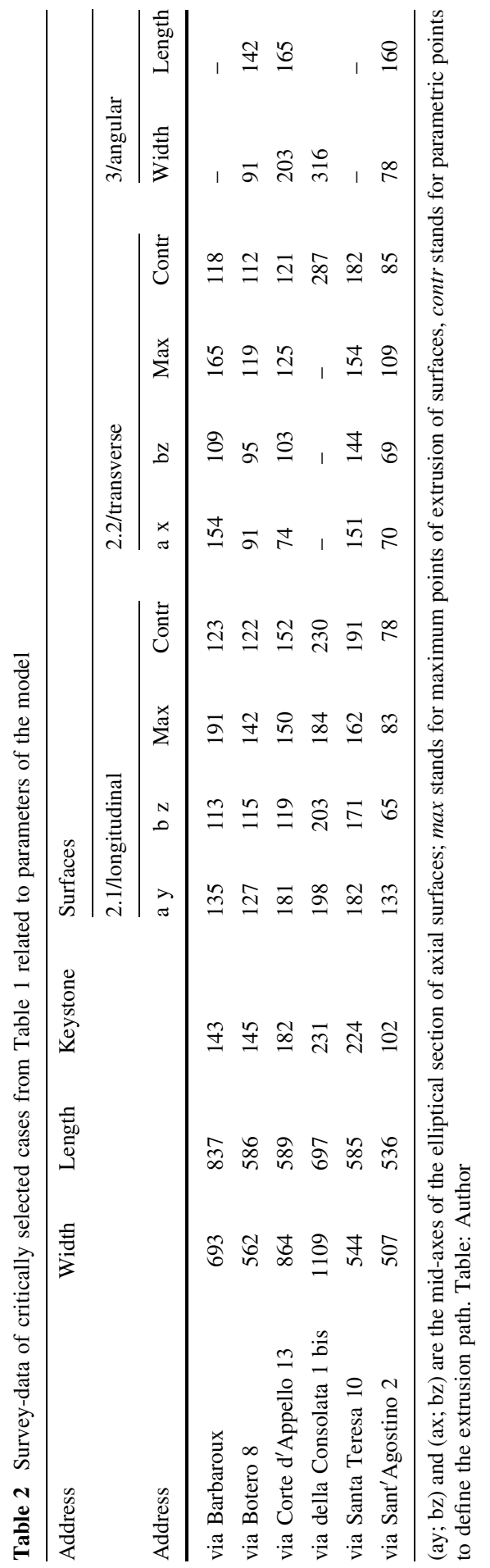




\section{Analysis of Results and Discussion}

Table 2 was created after the theoretical model was realised: it shows the surveydata needed to attribute values to parameters in order to obtain the model of selected cases from Table 1.

The selected cases have been chosen with regard to the desire to test the efficiency of the parametric model with the different geometric configuration taking into account the high variability in dimensional and qualitative terms:

- Dimensional: Both absolutely and relatively, the cases differ due to the different partitions of the rooms, the ratios between spans and heights, etc.

- Qualitative: The individual cases also differ in the absence of some of the surfaces that characterize the general pattern (longitudinal or transverse axial surfaces, angular surfaces).

After assigning the correct values to the parametric model, the configurations of the individual cases were obtained. As shown in Fig. 11, the model reacts with adequate flexibility to changes in the geometric-dimensional configuration for the individual cases. The model reacts positively in the cases that most closely adhere to the standard configuration of any Planterian vault (Via Corte d'Appello 13, Via
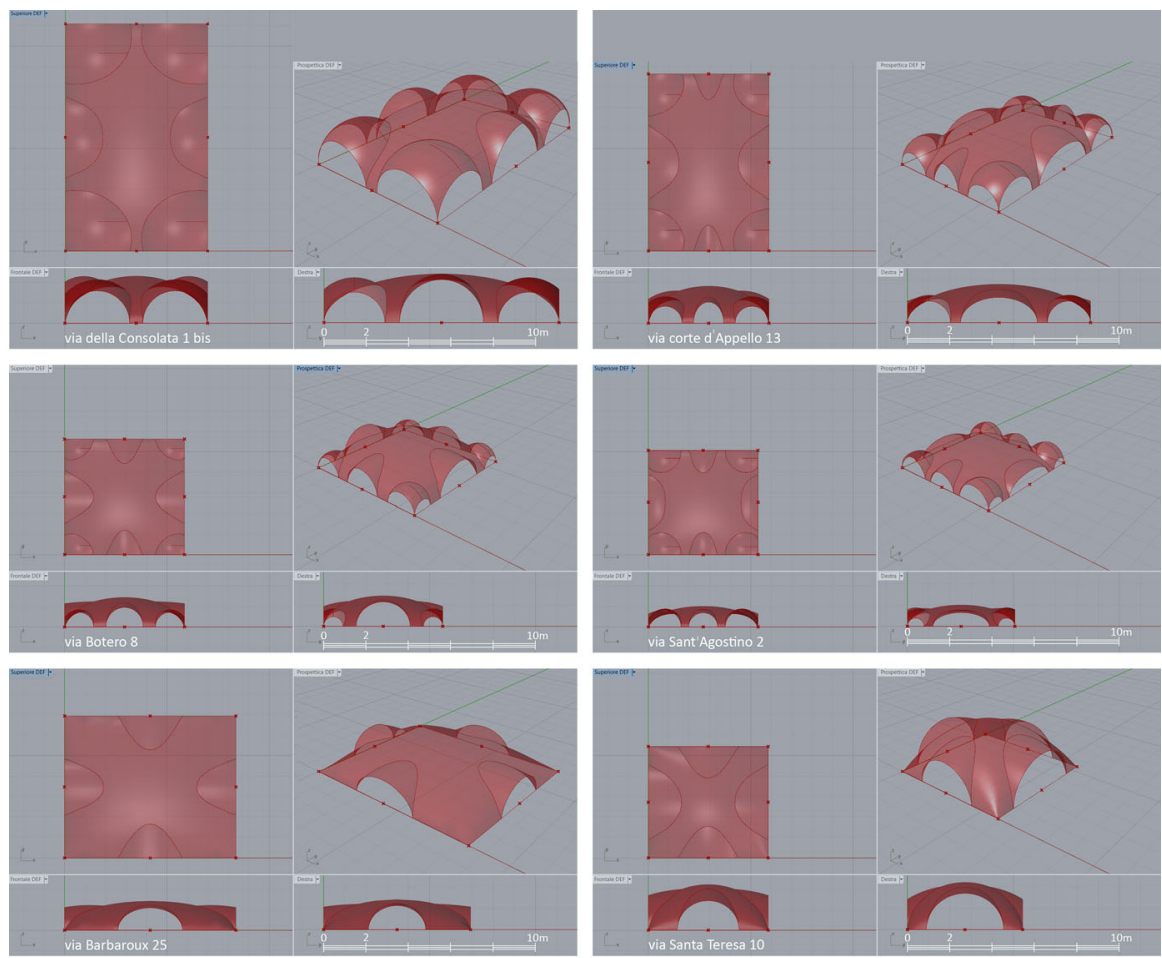

Fig. 11 Synoptic representation of selected cases using the parametric model: plan, elevations and perspective views. Models: Author 
Botero 8, Via Sant'Agostino 2), in which are found all the parametrized surfaces, albeit with different dimensional values (as highlighted in Table 2) and with different secondary surfaces (straight or inclined barrel vaults, toric surfaces).

Moreover, the model also effectively adjusts itself in the cases in which some parameters assume a value of 0 :

- In the case of Via della Consolata 1bis (Palazzo Saluzzo Paesana) the short sides of the perimeter are divided in only two portions, cancelling the axial transverse surface. The parameters related to its geometry assume a value of 0 and the model shows correctly the geometric configuration of the vault (the same result, less common, can be reached with axial longitudinal surfaces)

- In the cases of Via Barbaroux 25 (Palazzo Perucca della Rocchetta) and Via Santa Teresa 10 (Palazzo Riche di Coassolo) there are no angular vaults, simulated by decoration in Via Barbaroux 25 and cancelled by a significant increase in the size of axial surfaces (longitudinal e transverse) in Via Santa Teresa 10: the parameters related to the angular surfaces assume a value of 0 .

The results confirm the predictions in Table 1: the analysed cases, selected from among those considered adequate, are parametrized with a good level of approximation related to actual architecture. However, as the table shows, there are some cases in which the parametric model does not adequately represent the characteristics of the vaults (Fig. 12).

This occurs when the atrium has a different plan diagram (octagonal, as in Via Garibaldi 28) or a geometric logic of 'cuts and fills', as in the first works by Plantery (Palazzo Novarina, Via Santa Chiara 8; Palazzo Cigliano, Via Barbaroux 28). In some of these examples the angular vaults also have a significantly higher level of complexity than the generic model, as in Via Carlo Alberto 32 (Palazzo San Martino di Parella) or in Via Carlo Alberto 16 (Palazzo Birago di Borgaro). In other cases, the model more successfully adheres to the architecture, albeit partially (adequately but with some deviation) (Fig. 13), such as when the main surface is slightly different from an 'a conca' vault (i.e., a cloister vault, as in Via Garibaldi 24 or for 'cuts and fills' angular surfaces, as in Via Santa Chiara 20).
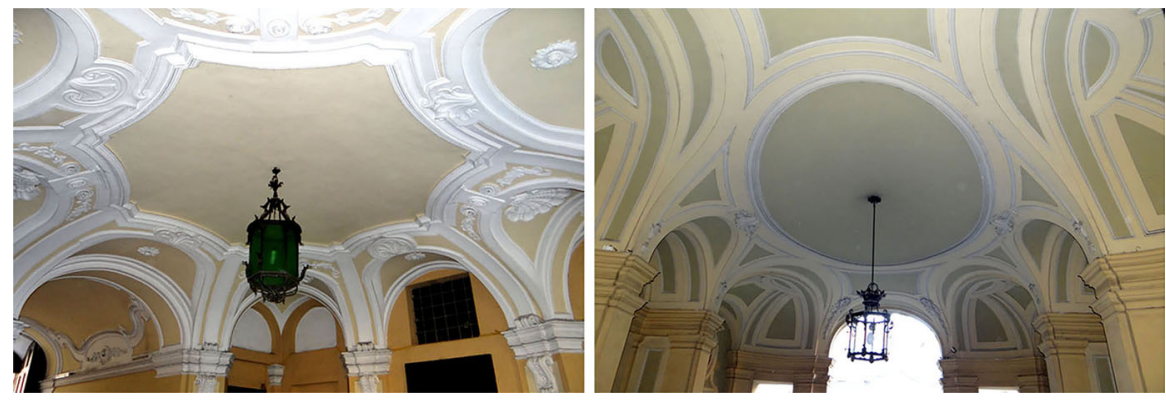

Fig. 12 Cases in which the parametric model does not adequately represent the characteristics of the vaults. This occurs when the atrium has a different plan diagram (via Garibaldi 28-Palazzo Fontana di Cravanza, attributed Plantery) or/and when the angular vaults have a significantly higher level of complexity (via Carlo Alberto 32-Palazzo San Martino di Parella). Photo: Author 

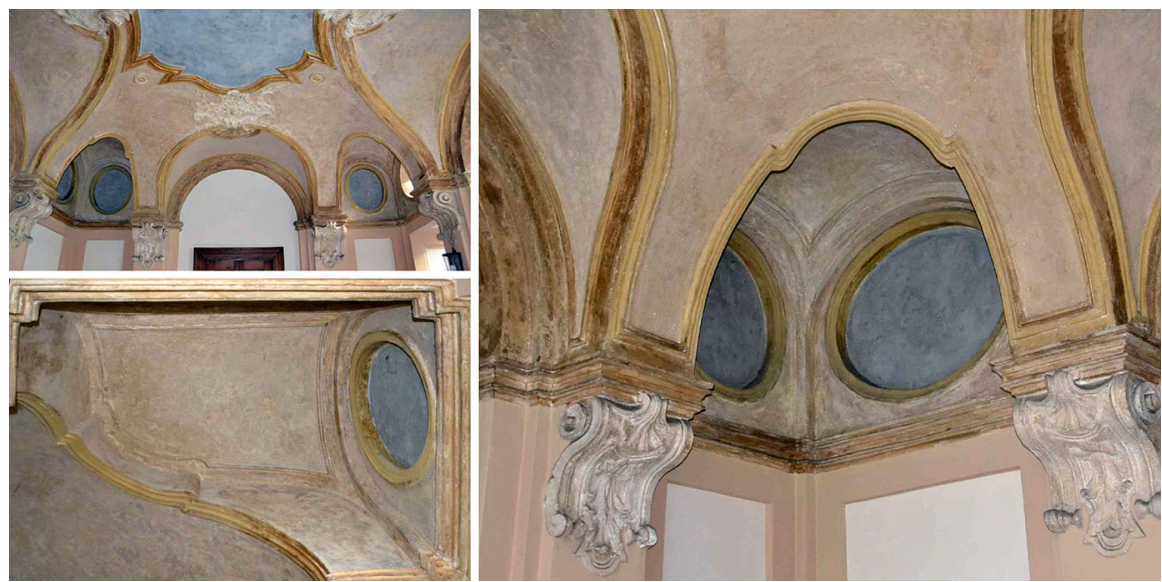

Fig. 13 via Santa Chiara 20 (Casa Martin Di Montù Beccaria): the model adheres to the architecture, albeit partially (adequately but with some deviation): the angular surfaces are realised by 'cuts and fills'

As for the relationship between parametric modelling and mathematical modelling this work highlights some interesting aspects. While, as said, mathematical modelling is a fascinating goal, it seems difficult to apply, especially on existing architecture: the difficulty of linking the mathematical formulation to survey data (i.e. the measurement of distances between physical entities identified on the real object) makes the process of analysis and construction of the model unwieldy and difficult to manage. Also, the construction of the model follows a process that is the reverse of that of the conception of shapes since it begins with the analysis of punctual features (as for example surface sections) that can be used to generate formulas for plane figures and not directly for the definition of formulas and parameters for complex surfaces in space. Another aspect to be considered regards the method of conducting survey: in this case the formal hypotheses and construction models (parametric and non-parametric) was based on a direct survey that involves a necessary and consistent discretization of the studied surface by sections (mainly vertical). This working method has much more in common, from a theoretical point of view and from an operational point of view, with parametric modelling. An instrumental survey (for example, with photo modelling and/or with a laser scanner) provide data that, although discrete but much less filtered, would be more easily comparable with a mathematical conceptualization of the surfaces involved.

Changing the field of investigation is certainly interesting to test the mathematical modelling approach to the architectural project (Peters and Peters 2013; Pottmann et al. 2007), where it follows the logical path of the creation of shapes in space, whether constructible physical entities or theoretical geometrical elements: also evident in this context are the connections between mathematical formulation and structural performance.

It seems possible to say that the survey can profitably make use of parametric modelling when it is oriented to the study of classes of homogeneous objects: thus, a 
parametric model for studying and analysing Planterian vaults is a very important research development, in that it links the parametric model to the survey data and makes it possible to study and compare the geometry of the vaults. This is a worthwhile goal because of the possibilities that it might provide for future research. After defining the parametric model, any analysis might then be approached in a new and more productive way with the aim of fixing parameters for the characteristics of reference, as well as varying some other parameters. This should enable validation of different conjectural readings of existing architecture by comparing the intersections between real and virtual surfaces. In this regard, the obtained parametric model is an interesting result that permits, working by comparisons, an analysis from a geometrical point of view of the intersections of double curvature surfaces: by varying the parameters defined for the construction of surfaces, considerations on their influence in the definition of the intersections can be made, with interesting consequences for research and for the teaching of descriptive geometry.

In addition, we intend to proceed by evaluating the possibility of setting up a new model for star-shaped vaults, with an awareness of the difficulties that would result in a higher level of variability of geometric conformation. Another useful aspect would be the possibility of realising a new version of the parametric model presented with a different logic of construction. In this phase, the model was achieved entirely in Grasshopper, but similar results could be obtained by creating the model in Rhinoceros and only using Grasshopper for parameterization. The comparison of the two different approaches and the resulting construction procedures may lead to interesting general considerations in three-dimensional parametric modelling applied to analyses and surveys.

\section{References}

Cavallari Murat, Augusto. 1957. Gian Giacomo Plantery, architetto barocco. Atti e Rassegna Tecnica della Società degli Ingegneri e degli Architetti in Torino 11 (7): 313-346.

Cavallari Murat, Augusto. 1968a. Indicazioni tradizionali di 'commodus, firmitas, venustas'. In: Forma urbana ed architettura nella Torino barocca: dalle premesse classiche alle conclusioni neoclassiche, Politecnico di Torino - Istituto di Architettura Tecnica, research directed by Augusto Cavallari Murat, vol. I, tomo 1, 99-113. Torino: UTET.

Cavallari Murat, Augusto. 1968b. L'organizzazione del nucleo particolare dei locali principali di ingresso, di distribuzione e di ricevimento. In: Forma urbana ed architettura nella Torino barocca: dalle premesse classiche alle conclusioni neoclassiche, Politecnico di Torino - Istituto di Architettura Tecnica, research directed by Augusto Cavallari Murat, vol. I, tomo 1, 643-667. Torino: UTET.

Crugnola, Gaetano. 1883-1908. Dizionario tecnico di Ingegneria e di Architettura. 5 vols. Torino: Negro. Curioni, Giovanni. 1868. Geometria pratica applicata all'arte del costruttore. Torino: Negro.

Dardanello, Giuseppe, Susan Klaiber and Henry A. Millon. 2006. Guarino Guarini. Torino: Allemandi.

Davis, Daniel. 2013. Modelled on Software Engineering: Flexible Parametric Models in the Practice of Architecture. Ph.D. thesis. Royal Melbourne Institute of Technology.

Migliari, Riccardo. 2012. Descriptive Geometry: From its Past to its Future. Nexus Network Journal 14 (3): 555-571.

Piccoli, Edoardo. 1999. Strutture voltate composte nell' architettura civile piemontese del XVIII secolo: le volte 'planteriane'. Palladio, 23: 87-100. 
Piccoli, Edoardo. 2001. Le strutture voltate nell'architettura civile a Torino, 1660-1720. In: Sperimentare l'architettura: Guarini, Juvarra, Alfieri, Borra e Vittone, ed. Giuseppe Dardanello, 38-96. Torino: Fondazione CRT.

Peters, Brady and Terri Peters. 2013. Inside Smartgeometry. Expanding the Architectural Possibilities of Computational Design. Chichester, West Sussex, United Kingdom: John Wiley \& Sons Ltd.

Pottmann, Helmut, Andreas Asperl, Michael Hofer and Axel Kilian. 2007. Architectural Geometry. Exton, Pennsylvania USA: Bentley Institute Press.

Spallone, Roberta and Marco Vitali. 2012a. Architettura - ri-Costruzione - Geometria: un percorso conoscitivo applicato allo studio delle volte 'planteriane' in Torino. DISEGNARE CON 5 (9): 187-196.

Spallone, Roberta and Marco Vitali. 2012b. Metodo geometrico, disegno costruttivo e tecniche di realizzazione fra trattatistica e arte di edificare. Esiti architettonici nelle volte 'planteriane'. In: Rappresentazione e progetto. La formalizzazione delle convenzioni del disegno architettonico, Roberta Spallone, 69-88. Alessandria: Edizioni dell'Orso.

Spallone, Roberta and Marco Vitali. 2012c. Between theory and praxis: the invention of Plantery's vaults between geometric thinking and building techniques. In: In praise of theory. The fundamental of the disciplines of representation and survey, $34^{\text {th }}$ Convegno internazionale dei docenti della Rappresentazione Conference Proceedings (Roma, December 2012), eds. L. Carlevaris and M. Filippa, 125-132. Roma: Gangemi.

Spallone, Roberta and Marco Vitali. 2015. Star-shaped and planterian vaults between Seventeenth and Eighteenth century in the entrance halls of Turin. From the contributions of the treatises, to the geometric modeling, to the survey of artifacts. DOMES AND CUPOLAS, 2 (1): 21-38.

Spallone, Roberta. 2016. Delle volte, e vari modi di farle. Interpretative digital models of the XIX and XX plates in Guarini's Architettura Civile, between designs and buildings. In: The Reasons of Drawing. Thought Shape and Model in the Complexity Management (38th Convegno Internazionale dei Docenti della Rappresentazione Conference Proceedings, Firenze, September 2016), Eds. S. Bertocci and M. Bini, 1275-1282. Roma: Gangemi.

Vitali, Marco. 2016. Geometric readings on built architecture: design paradigms and atria in Turin between Seventeenth and Eighteenth centuries. In: The Reasons of Drawing. Thought Shape and Model in the Complexity Management (38th Convegno Internazionale dei Docenti della Rappresentazione Conference Proceedings, Firenze, September 2016), Eds. S. Bertocci and M. Bini, 661-666. Roma: Gangemi.

Marco Vitali earned a Ph.D. in Drawing and Survey for the protection of the housing stock and territorial heritage from the Politecnico di Torino, where he is currently a researcher in the Department of Architecture and Design (DAD). He currently teaches the "Drawing Laboratory", in the Bachelor in Architecture program, and the "Representation project-Fundamentals of Descriptive geometry" in the Bachelor in Design and Visual communication program. His research concerns the areas of architectural survey, urban and environmental survey, descriptive geometry and digital representation, fields in which he has published numerous articles and on which he has presented papers at International Conferences. 